\title{
ВЛИЯНИЕ РАЗМОЛА НА ТЕРМОДИНАМИЧЕСКИЕ СВОЙСТВА ЦЕЛЛЮЛОЗЫ
}

\author{
() И.И. Осовская", В.С. Байкова, Г.М. Полторацкий \\ Санкт-Петербургский государственный технологический университет \\ растительных полимеров, ул. Ивана Черных, 4, Санкт-Петербург, 198095 \\ (Россия), e-mail: iraosov@mail.ru
}

\begin{abstract}
На сегодняшний день нет единой точки зрения на механизм процессов, происходящих при размоле. Цель работы - установить зависимость между термодинамическими свойствами целлюлозы и связеобразующей способностью размолотых целлюлозных волокон. Объектом исследования служили образцы сульфатной беленой и небеленой целлюлоз из хвойных и лиственных пород древесины. В работе получены интегральные теплоты взаимодействия размолотых целлюлоз при времени размола 0-40 мин при 298 К; сняты изотермы сорбции паров воды в широком интервале относительных давлений паров воды. Большое внимание уделяется подготовке образцов для калориметрических измерений. Развиваются представления о влиянии редуцирующих групп на свойства целлюлозы и ее способность к связеобразованию при получении бумаги. Сделан вывод о возможном регулировании свойств целлюлозы на основе полученных термодинамических параметров размолотой целлюлозы.

Ключевые слова: сульфатная лиственная, хвойная целлюлозы, размол, фибриллирование, редуцирующие группы, термодинамические, бумагообразующие свойства целлюлозы, инклюдирование.
\end{abstract}

\section{Введение}

Размол бумажной массы является исключительно важным этапом технологии производства бумаги, в процессе которого стремятся придать волокнистому материалу свойства, необходимые для повышения связеобразующей способности целлюлозы и увеличения прочности бумажного листа [1-4]. Приходится признать, что до настоящего времени нет единой точки зрения на механизм процессов, происходящих при размоле.

Авторы ряда работ рассматривают воздействие размола на волокна с точки зрения увеличения набухания, связывая набухание с содержанием гемицеллюлоз. Однако количественное содержание гемицеллюлоз не является надежной характеристикой бумагообразующих свойств, поскольку в связеобразовании волокон наибольшую роль играют поверхностные слои, содержание гемицеллюлоз в которых составляет незначительную часть от их общего количества.

Исследование, выполненное нами с акцентом на результаты термодинамического метода, позволяет сделать вывод о значительном влиянии содержания редуцирующих карбонильных групп, образующихся в процессе подготовки целлюлозы для получения бумаги. В работе уделяется большое внимание подготовке целлюлозных волокон для калориметрических измерений.

Осовская Ираида Ивановна - заведющая кафедрой физической и коллоидной химии, кандидат химических наук, старший научный сотрудник, e-mail: iraosov@mail.ru Байкова Вероника Сергеевна - инженер кафедры физической и коллоидной химии,

e-mail: ellrelano@yandex.ru

Полторачєий Геннадий Матвеевич - заслуженный деятель науки, профессор кафедры физической и коллоидной химии, доктор химических наук, e-mail: iraosov@mail.ru

\section{Результаты исследования и их обсуждение}

Прежде чем перейти к обсуждению представленных в работе результатов о влиянии размола на термодинамические свойства целлюлозы, поясним нашу точку зрения экспериментальными данными, полученными в этой работе и ранее [5-6]. Объектом исследования служили промышленные образцы сульфатной беленой целлюлозы из хвой-

\footnotetext{
* Автор, с которым следует вести переписку.
} 
ных пород древесины Братского ЛПК с содержанием $\alpha$-целлюлозы - 95\%. Бумага, полученная из такой целлюлозы, несмотря на высокое набухание в воде (теплота смачивания - 18,5 кал/г.ц.) имела крайне низкую прочность, не превышающую 3500-4000 м. Это связано с малой способностью таких волокон к связеобразованию вследствие недостатка на поверхности волокон низкомолекулярных фракций целлюлозы, перешедших в раствор при щелочной варке. Следовательно, хорошее набухание и гидрофильные свойства, вопреки часто высказываемому мнению, не являются гарантией получения высоких показателей прочности бумажного листа. Однако их изменение в результате физических, химических или тех и других воздействий делает возможным приблизиться к правильному пониманию механизмов, происходящих при этом явлений. По нашему мнению, нельзя недооценивать роль концевых редуцирующих групп макромолекул целлюлозы в поверхностных слоях волокна. Экспериментально показано, что частичная поверхностная деструкция неразмолотых целлюлозных волокон, сопровождающаяся увеличением содержания редуцирующих карбонильных групп, способствует повышению прочности бумаги более чем на $40 \%$ [5]. Причем данный прием можно считать обязательным при альтернативных способах получения бумаги из неразмолотых волокон (в частности, аэроформованием) при дефиците воды.

Содержание низкомолекулярных фракций целлюлозы определяли по растворимости целлюлозы в $10 \%$ водном растворе гидроксида натрия. Известно [7, 8], что в $10 \%$ растворе $\mathrm{NaOH}$ растворяется фракция целлюлозы со степенью полимеризации (СП ${ }^{298}$ жвнк $)$ не более 100-150.

Регулировали содержание низкомолекулярных фракций посредством кислотного гидролиза в $10 \%$ растворе серной кислоты при температуре $90{ }^{\circ} \mathrm{C}$. Кислотный гидролиз целлюлозы относится к топохимическим реакциям, это позволило проводить гидролиз в течение времени, при котором разрыв гликозидных связей происходит на поверхности волокна. При более глубоком гидролизе наблюдается снижение прочности опытных отливок $(\mathrm{BL})$ и моноволокна $\left(\mathrm{BL}_{\mathrm{O}}\right)$, что видно из рисунка 1 и таблицы 1.

Экспериментальные данные, полученные нами $[5,6,9]$, показали, что для связывания смежных поверхностей неразмолотых целлюлозных волокон необходимо молекулярное фибриллирование с образованием карбонильных редуцирующих групп, а возможно, в некоторой степени нанофибриллирование. Нами проведена частичная поверхностная деструкция целлюлозы водным кислотным гидролизом. Можно отметить, что поскольку гидролиз ведется в гетерогенной системе, макрокинетика гидролиза определяется не только химической кинетикой процесса разрыва гликозидных связей, но и физической кинетикой диффузионного проникновения кислоты в материал. Об увеличении бумагообразующей способности целлюлозных волокон после частичного кислотного гидролиза свидетельствуют результаты, представленные на рисунке 1, из которых видно, что содержание на поверхности целлюлозных волокон 18-20\% низкомолекулярных фракций целлюлозы приводит к значительному увеличению прочности бумажного листа [5].

Частичная поверхностная деструкция волокон на молекулярном уровне увеличивает зону контакта между волокнами и, как следствие, прочность межволоконных связей при сушке бумажного листа. Обработка частично гидролизованных волокон натрийборгидридом $\left(\mathrm{NaBH}_{4}\right)$ с целью блокирования карбонильных групп целлюлозы показала снижение прочности бумаги из гидролизованных волокон, обработанных $\mathrm{NaBH}_{4}$, на 27\%. Частичная деструкция целлюлозы в процессе размола, повышая адгезионную способность его поверхности, снижает механическую прочность отдельного волокна (табл. 1).

Поэтому бумага, полученная из волокон с высокой связеобразующей способностью, имеющая высокое содержание низкомолекулярных фракций на поверхности волокна, может иметь низкие показатели механической прочности в связи с низкой прочностью самих волокон.

Исследование термодинамических свойств размолотых целлюлоз не противоречит гипотезе о роли концевых редуцирующих групп на связеобразование. В работе показано изменение термодинамических свойств целлюлозы в процессе размола. Объектами исследования служили промышленные образцы сульфатной (СФА) беленой и небелёной целлюлоз из хвойных и лиственных пород древесины.

Характеристика этих целлюлоз представлена в таблице 2.

Роспуск и размол целлюлозы проводился в дисковой мельнице при концентрации массы 6\%. Время размола составляло 0-35 мин. Отбор проб проводился с интервалом 5 мин. Степень помола ( $\left.{ }^{\circ} Ш \mathrm{P}\right)$ соответствовала для СФА беленой лиственной - 14,$0 ; 25,4 ; 37,1 ; 40,3 ; 43,2 ; 48,7 ; 52,9 ; 54,1 ;$ СФА беленой хвойной - 13,5; 23,7; 35,4; 38,9; 42,1; 42,8; 43,2; 45,3; СФА небеленой хвойной - 13,0; 22,7; 33,9; 38,0;41,4; 41,9; 42,$3 ; 43,0$. Определение степени помола, изготовление отливок и их испытания проводились по стандартным методикам. 
Таблица 1. Влияние содержания низкомолекулярных фракций (n) на прочность моноволокна $\left(\mathrm{BL}_{0}\right)$

\begin{tabular}{c|c|c|c}
\hline \multicolumn{2}{|c|}{ Сульфатная полубеленая } & $\mathrm{n}, \%$ & Сульфатная беленая \\
\hline $\mathrm{n}, \%$ & $\mathrm{BL}_{0}, \mathrm{M}$ & 6 & $\mathrm{BL}_{0}, \mathrm{M}$ \\
\hline 5,1 & 4100 & 7,5 & 2200 \\
7,5 & 4000 & 10 & 2100 \\
10 & 3900 & 15 & 2000 \\
15 & 3700 & 17,5 & 1600 \\
22 & 3000 & 23,8 & 1420 \\
25 & 2200 & & \\
\hline
\end{tabular}

Рис. 1. Влияние содержания коротких цепей (n) на прочность бумаги (BL). Целлюлоза: 1 - сульфатная полубеленая, 2 - сульфатная беленая

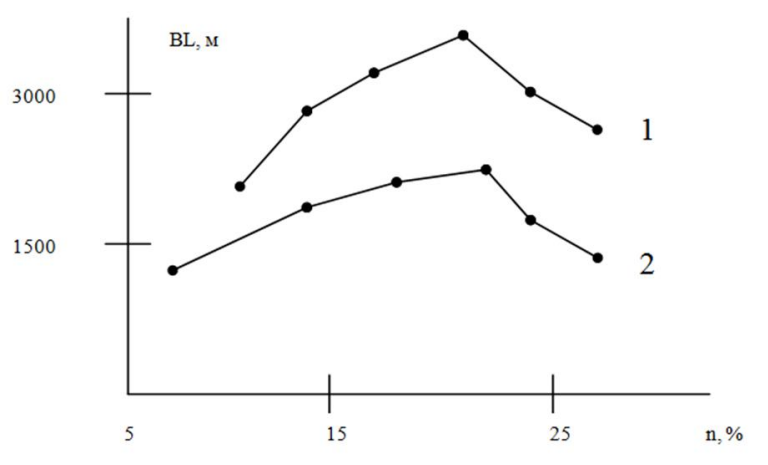

Таблица 2. Характеристика исследуемых целлюлоз

\begin{tabular}{|c|c|c|c|c|c|c|}
\hline Образец & $\begin{array}{c}\text { Содержание } \\
\alpha \text {-целлюлозы, \% }\end{array}$ & $\begin{array}{c}\text { Содержание } \\
\text { НМФ, \% }\end{array}$ & $\begin{array}{l}\text { Содержание } \\
\text { лигнина, \% }\end{array}$ & $\begin{array}{c}\text { Содержание } \\
\text { смол и жиров, \% }\end{array}$ & $\begin{array}{c}\text { Зольность, } \\
\%\end{array}$ & $\begin{array}{c}\text { Степень } \\
\text { помола, }{ }^{\circ} \text { ШР }\end{array}$ \\
\hline $\begin{array}{c}\text { СФА } \\
\text { беленая лиственная }\end{array}$ & 88,4 & 5,6 & 0,5 & 0,2 & 0,13 & 14,0 \\
\hline $\begin{array}{c}\text { СФА } \\
\text { беленая хвойная }\end{array}$ & 89,3 & 4,8 & 0,4 & 0,3 & 0,15 & 13,0 \\
\hline $\begin{array}{c}\text { СФА } \\
\text { небеленая хвойная }\end{array}$ & 80,9 & 8,0 & 7,6 & 0,8 & 0,4 & 11,5 \\
\hline
\end{tabular}

Интегральные энтальпии взаимодействия размолотых целлюлоз с водой $\left(-\Delta \mathrm{H}\right.$, кДж·кг $\left.{ }^{-1}\right)$ в зависимости от времени размола (степени помола) получены при 298 К на калориметре с изотермической оболочкой, относительная погрешность - $1 \%$.

Необходимо кратко остановиться на ряде трудностей методического характера, связанных с подготовкой образцов для калориметрии [5, 9]. Калориметрические измерения требуют абсолютно сухих образцов целлюлозы, так как малейшие количества влаги оказывают существенное влияние на измеряемые показатели, изменяя при этом физико-химические свойства целлюлозы вследствие ее активного взаимодействия с водой. Энергия этого взаимодействия не является линейной функцией содержания воды, поглощенной целлюлозой. В связи с этим режим обезвоживания целлюлозы имеет принципиальное значение для правильной интерпретации полученных результатов. В работе обезвоживание влажных размолотых образцов (степень помола 10-60 ШР) проводили двумя способами. По первому из них образцы сушили в стеклянных ампулах при температуре $378 \mathrm{~K}$ в вакууме над $\mathrm{P}_{2} \mathrm{O}_{5}$ до постоянной массы. По второму способу с целью сохранения капиллярно-пористой структуры целлюлозы воду вытесняли методом замены растворителей (сушка инклюдированием) [5, 6, 10].

Изотермы десорбции размолотых целлюлоз получены статическим методом при 298К. Для получения заданных относительных давлений паров воды $\left(\mathrm{p} / \mathrm{p}_{0}\right)$ использовали насыщенные растворы неорганических солей. Изотермы снимали при $\mathrm{p} / \mathrm{p}_{0}=0,35 ; 0,65 ; 0,84 ; 0,975$. Специальной подготовки образцов не требовалось. Результаты калориметрических исследований представлены на рисунках 2, 3.

Как видно из рисунков 2, 3, зависимость интегральных теплот взаимодействия целлюлозы с водой (теплот смачивания, $\Delta \mathrm{H}$ ) от времени размола (степени помола) имеет явно выраженные перегибы, обусловленные влиянием внешнего и внутреннего фибриллирования на изучаемые параметры. Причем перегибы на зависимости $\Delta \mathrm{H}=\mathrm{f}(\tau)$ характерны как для образцов, обезвоженных температурной сушкой, так и для инклюдированных образцов, сохраняющих структуру, приобретенную в результате размола. Наличие точек перегиба указывает на протекание противоположных процессов, каждый из которых влияет на сорб- 
цию паров воды (a), $\Delta$ Н целлюлозы и BL (рис. 2-6). Понижение теплот смачивания (рис. 2) связано с увеличением прочности водородных связей при сушке, предварительно необезвоженных инклюдированием образцов. Причем любые способы обезвоживания, кроме инклюдирования, не сохраняют приобретенную целлюлозой структуру при любом воздействии воды на волокно, в том числе и при размоле. При обычном высушивании (при низких температурах или под вакуумом [5, 10]), когда еще сохраняется влага, стенки пор достаточно эластичны, т.е. целлюлоза находится в высокоэластическом состоянии, но капилляры почти полые, так как основная часть воды уже удалена, поэтому стенки пор смыкаются и образуются те прочные водородные связи, которые снижают количество функциональных групп, взаимодействующих с целлюлозой с выделением тепла. Для сохранения структуры, приобретенной при размоле, необходимо, чтобы целлюлоза еще до полного удаления воды перешла в застеклованное состояние, что и происходит при удалении воды жидкостями, не взаимодействующими с целлюлозой и не снижающими температуру стеклования (ацетон, этанол, $\boldsymbol{H}$-гептан).

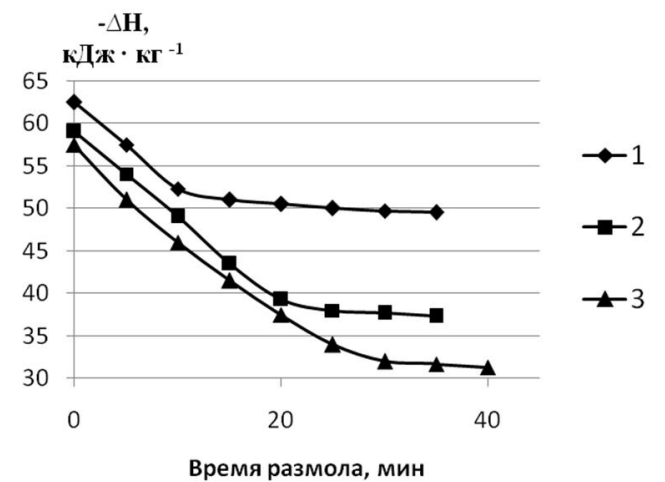

Рис. 2. Интегральные теплоты взаимодействия целлюлозы с водой. Обезвоживание целлюлозы при температуре 378 К: 1 - СФА беленая лиственная; 2 - СФА беленая хвойная; 3 - СФА небеленая хвойная

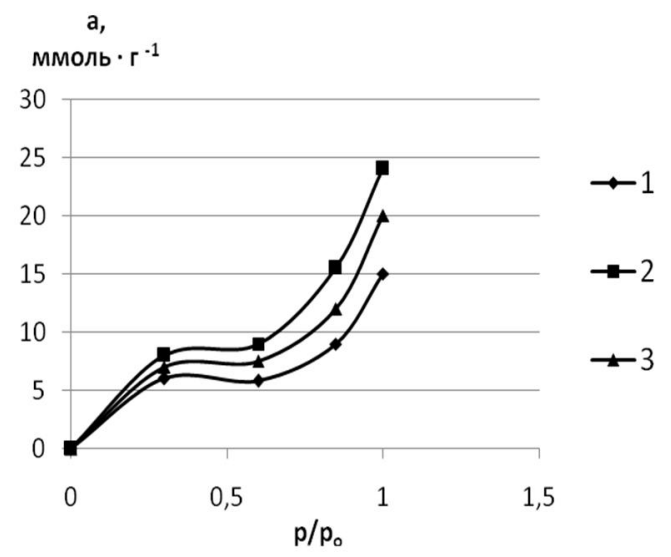

Рис. 4. Изотермы десорбции сульфатной беленой целлюлозы из лиственных пород древесины: 1 - без размола; 2 - размол в течение 10 мин; 3 - размол в течение 20 мин

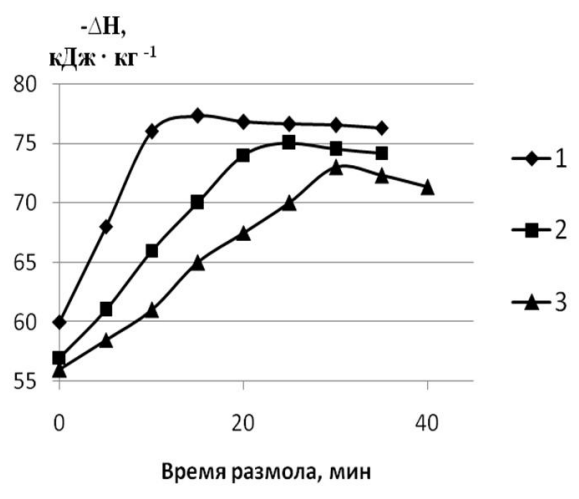

Рис. 3. Интегральные теплоты взаимодействия целлюлозы с водой. Сушка инклюдированной целлюлозы при температуре 378 К: 1 - СФА беленая лиственная; 2 - СФА беленая хвойная; 3 - СФА небеленая хвойная

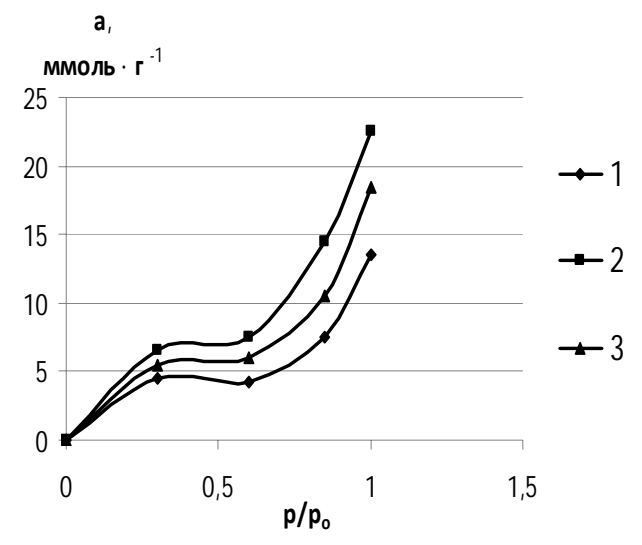

Рис. 5. Изотермы десорбции сульфатной беленой целлюлозы из хвойных пород древесины: 1 - без размола; 2 - размол в течение 20 мин; 3 - размол в течение 30 мин 
Рис. 6. Влияние размола на разрывную прочность бумаги: 1 - СФА беленая хвойная; 2 - СФА беленая лиственная

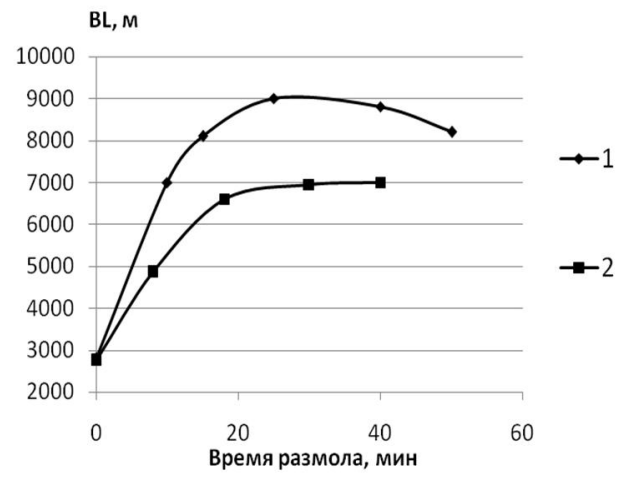

Повышение теплот смачивания инклюдированных образцов и сорбции паров воды в начальный период размола (рис. 3-5) связано не только с ослаблением водородных связей при размоле, но и с образованием новых сорбционных центров - карбонильных групп, образовавшихся в результате деструкции целлюлозы. Увеличение сорбирующей поверхности, обусловленное повышением подвижности образовавшихся коротких цепей, увеличение при этом концентрации карбонильных групп способствуют повышению прочности опытных отливок (рис. 6). С увеличением времени размола происходит снижение всех измеряемых параметров, обусловленное процессом прогрессирующей деструкции и, как следствие, вторичной кристаллизации, типичной для полимеров в высокоэластическом состоянии [11]. Причем вторичная кристаллизация и деструкция целлюлозы взаимно ускоряют друг друга. С одной стороны, кристаллизация создает напряжение в цепях, снижая энергию активации разрыва; с другой стороны, разрыв цепей облегчает процесс кристаллизации, ускоряя его протекание. С прогрессирующей деструкцией с увеличением времени размола связано также снижение прочности опытных отливок (рис. 6).

\section{Выводbl}

1. Исследование влияния коротких цепей макромолекул целлюлозы на термодинамические характеристики позволяет выдвинуть гипотезу о влиянии концевых редуцирующих групп на связеобразующую способность целлюлозы в процессе её подготовки для получения бумаги.

2. Получение зависимостей термодинамических параметров целлюлозы от времени размола позволяет сделать вывод о возможном регулировании свойств целлюлозы при ее подготовке для получения бумаги.

3. Полученные интегральные теплоты взаимодействия размолотых целлюлоз с водой показали принципиальное различие способов подготовки образцов на толкование полученных результатов термохимического анализа.

\section{Список литературь}

1. Кларк Дж. Технология целлюлозы / пер. с англ. А.В. Оболенской, Г.А. Пазухиной. М., 1983. 456 с.

2. Дулькин Д.А., Блинова П.А., Блинушова О.И. Изменение надмолекулярной структуры волокнистых полуфабрикатов из древесины в процессе размола // Химия растительного сырья. 2007. №1. С. 75-83.

3. Аким Э.Л., Абрамов И.Н. Размол как путь направленного изменения физико-механических свойств композиционных материалов на основе целлюлозы из лиственницы // Целлюлоза. Бумага. Картон. 2012, №6. С. 38-44.

4. Смолин А.С., Бисальски М. Влияние размола и фракционирования на электроповерхностные свойства целлюлозных гидросуспензий // Химия растительного сырья. 2011. №3. С. 183-192.

5. Осовская И.И., Полторацкий Г.М., Дмитриева Е.А. Гидрофильные свойства целлюлозы, обработанной насыщенным паром // Журнал прикладной химии. 2005. Т. 78, №7. С. 1203-1207.

6. Азаров В.И., Буров А.В., Оболенская А.В. Химия древесины и синтетических полимеров : учебник для вузов. СПб., 2009. 628 c.

7. Оболенская А.В., Ельницкая 3.П., Леонович А.А. Лабораторные работы по химии древесины и целлюлозы. M., $1991.512 \mathrm{c}$.

8. Аксельрод Г.З., Смолин А.С., Трухтенкова М.Е. Термодинамическое исследование системы целлюлоза - вода // Сборник трудов ВНИИБ. СПб., 1973. С. 59-68.

9. Байкова В.С., Ковалев Д.С., Осовская И.И. Исследование сорбционных и гидрофильных свойств модифицированных форм целлюлозы // Современные проблемы науки о полимерах: тез. докл. научной конференции молодых ученых. СПб., 2013. С. 92.

10. Урьяш В.Ф. Влияние степени упорядоченности на термохимические характеристики целлюлозы и растворимость воды в ней // Журнал физической химии. 2005. Т. 79, №8. С. 1383-1387.

11. Аким Э.Л. Обработка бумаги. М., 1979, 232 с. 
Osovskaia I.I. ${ }^{*}$ Baikova V.S., Poltoratskii G.M. INFLUENCE OF GRINDING ON THE THERMODYNAMIC PROPERTIES OF CELLULOSE

St. Petersburg State Technological University of Plant Polymers, Ivana Chernykh st., 4, St. Petersburg, 198095

(Russia),e-mail:iraosov@mail.ru

Today no single point of view on the mechanism of the processes occurring during the grinding. Objective: to determine the relationship between the thermodynamic properties of cellulose and the ability to form relationships milled cellulose fibers. The object of the study were samples of Kraft bleached and unbleached pulps from coniferous and deciduous wood. In the work received the results of the integral heat of interaction milled cellulose at the time of grinding 0-40 min at $298 \mathrm{~K}$; removed isotherms of water vapor sorption in a wide range of relative vapor pressures of the water. Much attention is paid to the preparation of the samples for the calorimetric measurements. Develop presentation on the influence of reducing groups on the properties of cellulose and its ability to form relationships upon receipt paper. The conclusion about possible regulation of cellulose on the basis of the obtained thermodynamic parameters of milled cellulose.

Keywords: a sulfate hardwood pulp, a softwood pulp, a grinding, a brushing, a reducing groups, a thermodynamic properties of a pulp, a papermaking properties of a pulp, a inclusion.

\section{References}

1. Klark Dzh. Tekhnologiia tselliulozy. [Technology cellulose]. Moscow, 1983, 456 p. (in Russ.).

2. Dul'kin D.A., Blinova P.A., Blinushova O.I. Khimiia rastitel'nogo syr'ia, 2007, no. 1, pp. 75-83. (in Russ.).

3. Akim E.L., Abramov I.N. Tselliuloza. Bumaga. Karton, 2012, no. 6, pp. 38-44. (in Russ.).

4. Smolin A.S., Bisal'ski M. Khimiia rastitel'nogo syr'ia, 2011, no. 3, pp. 183-192. (in Russ.).

5. Osovskaia I.I., Poltoratskii G.M., Dmitrieva E.A. Zhurnal prikladnoi khimii, 2005, vol. 78, no. 7, pp. 1203-1207. (in Russ.).

6. Azarov V.I., Burov A.V., Obolenskaia A.V. Khimiia drevesiny $i$ sinteticheskikh polimerov. [Wood chemistry and synthetic polymers]. St. Petersburg, 2009, 628 p. (in Russ.).

7. Obolenskaia A.V., El'nitskaia Z.P., Leonovich A.A. Laboratornye raboty po khimii drevesiny i tselliulozy. [Laboratory work on the chemistry of wood and cellulose]. Moscow, 1991, 512 p. (in Russ.).

8. Aksel'rod G.Z., Smolin A.S., Trukhtenkova M.E. Sbornik trudov VNIIB. [Proceedings VNIIB]. St. Petersburg, 1973, pp. 59-68. (in Russ.).

9. Baikova V.S., Kovalev D.S., Osovskaia I.I. Sovremennye problemy nauki o polimerakh: tez. dokl. nauchnoi konferentsii molodykh uchenykh. [Modern problems of polymer science: abstracts of scientific conference of young scientists]. St. Petersburg, 2013, pp. 92. (in Russ.).

10. Uriash V.F. Zhurnal fizicheskoi khimii, 2005, vol. 79, no. 8, pp. 1383-1387. (in Russ.).

11. Akim E.L. Obrabotka bumagi. [Paper handling]. Moscow, 1979, 232 c. (in Russ.).

Received Juny 18, 2014

Revised October 7, 2014

\footnotetext{
* Corresponding author.
} 